\title{
Reading Psalm and Prayer Manuscripts From Qumran
}

The Qumran Caves provided a treasure trove of manuscripts containing psalms and prayers. Of the over 900 manuscripts from the caves, almost a sixth have been classified by their official editors as manuscripts that contain, at least in their present state of preservation, only psalms or prayers. In addition, there are a number of psalms and prayers as part of narrative works (e. g., 1QS, 1QM, and Jubilees). Much has already been written on many of these works, like the so-called psalms manuscripts and the Hodayot, and estimations have been made about the extent of the collections of psalms and prayers in individual manuscripts and their possible use. Sometimes these assessments have been based mostly on the contents of the collection, at other times on the material formats, and in a few instances these have been combined. ${ }^{1}$ Mostly the arguments have claimed either a private use or a public, ritual, use. Furthermore, such assessments have typically been made by determining the size of the manuscript and the plausible extent of its contents, and consequently in what settings such a scroll could most probably have been used.

Thus far there have been no attempts to provide a complete overview of the psalm and prayer material from Qumran focusing on matters that are more directly related to the actual reading of a manuscript than its overall dimensions, i. e., script size and spacing of lines, letters, and words. ${ }^{2}$ I will provide such an overview of the material in this article, drawing attention to features shared by these manuscripts and the works in them. I will furthermore provide an estimate of the standard spacing used in these manuscripts, which allows for manuscripts markedly deviating from these standards to be more easily recognized for closer inspection in the future. ${ }^{3}$ Naturally such an analysis is based on probabilities and averages and cannot be used to give absolute answers concerning the use of specific manuscripts. It is thus suggestive rather than conclusive. But the size of the collection of manuscripts from Qumran containing

1 See, for instance, Nitzan 1994; Falk 1998; Falk 2000; Flint 1997; Schuller 1999a; Schuller 1999b; Pajunen 2014; Pajunen 2015.

2 An exception to this is provided by Falk 2014 who has surveyed all the prayer manuscripts from Qumran and part of the psalm manuscripts with an emphasis on their material features, including script size and line division. He excludes from his study the manuscripts containing now biblical psalms and the most fragmentary of the psalm and prayer manuscripts. Falk does make some observations on readability on a couple of occasions, but his main concern is the general size and quality of the different scrolls that relate, for instance, to their portability and considerations of economy. 3 The measurements given in this article are based on information given by the editors of the individual manuscripts in the official DJD editions that I have double-checked, and when this information is lacking, on my own calculations.

Ә Open Access. (C) 2020 Mika S. Pajunen, published by De Gruyter. (c) BY-NC-ND This work is licensed under the Creative Commons Attribution-NonCommercial-NoDerivatives 4.0 License. 
psalms and prayers is significant and can therefore be used to establish certain norms to distinguish manuscripts that fall outside them. Each of these manuscripts then needs to be considered carefully on its own in further studies before drawing firmer conclusions on its intended use.

There are over 140 manuscripts among the Qumran finds that the official editors have classified as psalm or prayer manuscripts. These manuscripts provide the material for this investigation as ritual use has often been considered the primary one for works containing psalms and prayers. ${ }^{4}$ This does not mean that psalms and prayers in narrative contexts could not have been used for such ends, but when they are part of a narrative their formatting follows that of the overall work in terms of readability, which means their possible use in liturgies would have to be based solely on internal evidence. ${ }^{5}$ Some manuscripts out of these c. 140 are very small individual pieces and their identification as psalms or prayers is quite uncertain. The twenty most uncertain cases (1Q37, 4Q411, 4Q249m, 4Q249n, 4Q249o, 4Q439, 4Q446, 4Q447, 4Q450, 4Q452, 4Q453, 4Q454, 4Q468k, 4Q476, 4Q476a, 4Q498, 4Q499, 4Q500, 4Q527, and 4Q579b) have, therefore, been excluded from this study. ${ }^{6}$ In addition to these excluded manuscripts, there are a few other manuscripts, possibly containing a psalm or a collection of psalms now in the MT Psalter, where the identification is based on only a few partially preserved words. These are currently included in the corpus of this study but are not taken up as significant evidence for possible deviations from standard practices because so little is preserved. The corpus of manuscripts that has been used in this investigation thus consists of 119 manuscripts. ${ }^{7}$ In the following I will first present some of the typical features of these manuscripts and then showcase some especially intriguing cases that deviate from the common norms of this corpus in significant ways.

4 This matter is not as straightforward as has often been suggested and in recent studies I have shown that psalms and prayers were also used for educational and prophetic purposes. See, e. g., Pajunen 2013; Pajunen 2017; Pajunen 2019. Nevertheless, psalms and prayers continued to be used in liturgies, and many of the psalm and prayer collections from Qumran, like the Berakhot, Songs of the Sabbath Sacrifice, and Daily Prayers, seem to be meant primarily for such a use. The compositions investigated more closely in this article for possible public ritual use or private piety all have contents that suggest a liturgical function as the primary one.

5 An exception to this is $4 \mathrm{QDeut}^{\mathrm{q}}$ (4Q44), which seems to have originally contained only the Song of Moses known from Deuteronomy 32. Because this manuscript only contains this song and none of the surrounding narrative, the manuscript has been included in this survey.

6 In addition, while the tefilim and mezuzot from Qumran can be argued to have had a ritual use, they are most of all ritual objects and the script on them is of miniature size, which rules out their regular reading altogether. They have, therefore, been excluded from this study. On the tefilim and mezuzot see Cohn (in this volume).

7 The cataloging of papyrus manuscripts in the official editions is somewhat misleading. Separate works on the same opisthographic manuscripts have been assigned separate manuscript numbers (like 4Q503 and 4Q512). While the individual works on the opisthographs are referred to in this study by these numbers, the numbering of the manuscripts counts each opisthograph as a single manuscript, regardless of how many works were included in it. 


\section{Typical Characteristics of Psalm and Prayer Manuscripts From Qumran}

In the following, attention will be paid especially to those aspects that directly pertain to the readability of these psalm and prayer manuscripts in a public or private ritual setting. Most of these factors pertain to the material format of the manuscripts but a few are also related to the content of the works. Material indicators are the primary factors here, content providing only an auxiliary function. First of all, the language of psalms and prayers was clearly Hebrew. ${ }^{8}$ All of these psalm and prayer manuscripts are in Hebrew and prayers in Aramaic are only found in narrative works also otherwise in Aramaic, such as the Genesis Apocryphon and the Aramaic Levi Document. Second, the preferred writing material was animal skin, with only seven of the 119 manuscripts being papyrus manuscripts and the rest on parchment. ${ }^{9}$ Third, nearly all of the collections, containing enough material to establish this, use vacats for demarcating the collected compositions. Some of the manuscripts provide even more minute sense divisions into strophes, but already an empty space just between separate compositions would have helped potential readers in locating specific compositions. In some manuscripts the easy location of prayer and psalm beginnings is further facilitated by special signs in the margin that allow for a quick browsing to the appropriate section (cf. 4Q414, 4Q503, 4Q504, and 4Q506/4Q509). This feature will be returned to later in this article. In only a few cases is there enough existing content to suggest that vacats were not used in a particular manuscript even between consecutive compositions. The lack of clear sense divisions would have hindered the easy use of these manuscripts in both public reading and in private use relying on easy identification of appropriate prayers or psalms. This feature can hence be used together with other criteria to argue that a specific manuscript was not formatted for use in a public gathering. At this point it is pertinent to point out that this is the furthest it is possible to go, i. e., it is possible to argue that some manuscripts were not formatted for public use whereas some may have been primarily intended for such practices, but whether or not the format completely excluded their use in other fashions cannot

8 Obviously the choice of language is not a material feature, but it is necessary to recognize the predominance of Hebrew regarding psalms and prayers as well as in some other genres, such as legal texts. Possible reasons for the preference of Hebrew in these genres can then be discussed in further studies.

9 Tov 2004, 45 indicates that $14 \%$ of the manuscripts from Qumran were written on papyri. The papyrus manuscripts in this survey make up only $6 \%$ of the entire corpus of psalm and prayer manuscripts, which demonstrates that papyrus was even more seldom used for such compositions than for other kinds of works. Falk 2014, 42-43 arrives at slightly different percentages because he criticizes Tov's overall numbering of papyrus manuscripts from a number of different standpoints. In his estimation the percent of papyrus prayer manuscripts from Qumran is close to the overall percentage of papyrus manuscripts among the finds that he calculates as c. $10 \%$. 
be demonstrated. A fourth feature common to nearly all of these manuscripts is that they are written in a formal or semi-formal hand, which would have helped with their reading, both aloud and in private. Only a couple of manuscripts are written in cursive script, which has sometimes been argued to indicate private use. These features are the four most common elements in the psalm and prayer manuscripts. A typical psalm or prayer manuscript from Qumran would thus have been written in Hebrew in a formal or semi-formal hand on a parchment manuscript and the scribe would have employed vacats to show at least the divisions between different compositions.

The actual format and scale of these manuscripts varies a great deal, as do the contents. In these matters the typical norm can be established by placing the manuscripts on a spectrum where the middle provides the most typical configuration, and by further highlighting certain practices used only with particular contents. Manuscript size varies a great deal and, in most cases, the original size of a collection can no longer be estimated. Really small manuscripts that originally contained only a few lines were probably short as well. These have often been claimed to contain material for private use or even, combined with other criteria, to have been amulets. ${ }^{10}$ In turn, scrolls that have a large writing block seem to have been usually meant for containing larger collections that often also seem to be written in a crowded fashion to exclude easy use in public gatherings. Public use is, thus, unlikely regarding manuscripts in both of these extremes. But most of the material falls in between these extremes and in these cases the height of the manuscript and its column width cannot be used to argue for or against a possible usage.

A related matter is manuscripts completely or partly written in a stichometric arrangement. These formats are only used for some of the now biblical psalms, and possibly for some psalms in 4QNon-Canonical Psalms A (4Q380), ${ }^{11}$ and in my view the arrangement relates to the clear classic Hebrew parallelism used in many of the early psalms but typically not employed in psalms from the late Second Temple period. Consequently, because of the lack of classic parallelism, many of the now biblical psalms and nearly all of the apocryphal psalms appear to be unsuited for a stichometric format and are written in a prose format instead. Whether a stichometric arrangement is connected with the intended usage of a particular manuscript cannot be established. In some cases this might be possible, but in my view the use of this particular arrangement in the case of certain psalms relates most of all to preserving their traditional format that is related to their use of classic parallelism. That some of the manuscripts contained both stichometrically arranged and prose format psalms (e.g., 1Q10) supports this conclusion as does the use of stichometric arrangement in some psalms that are

10 This has been suggested, for instance, by Kipp Davis in an unpublished paper presented in Helsinki in 2015.

11 For an assessment of the codicological features of stichometrically arranged manuscripts and for a critique of the notion that this arrangement would reflect the authority of a composition, see Davis 2017. 
part of narrative compositions. The extensive use of stichometric formatting in a manuscript does mean that it is highly improbable that such a manuscript could have contained something like a 150-psalm psalter because of the needed space, but such an arrangement alone does not help with indicating or excluding a public use. However, it should be noted that where a stichometric arrangement of a psalm was employed, it would have helped with the recitation of the psalm in question because the individual cola of the psalm are clearly defined. But of course this added readability would have been true for both public and private use of such manuscripts.

Perhaps the most important factor in the layout of a manuscript for arguing for or against its easy readability is the size of the script and the divisions between lines, letters, and words. There is naturally some variance in these measurements inside individual manuscripts but a consistent use of large characters with extensive spacing probably denotes a limited collection of works that was easy to read in public. Conversely, a scroll written consistently with uncharacteristically small letters with crowded letter, word, and line spacing would have been very difficult to use in a public reading setting. Most of the manuscripts naturally fall in between these extremes and they could easily have been used in both public and private spheres. Many manuscripts also contain one abnormality in these matters but otherwise fit into the regular format. A case could be made for some of these, in combination with other criteria, but they are not dealt with more thoroughly in this article because it would necessarily mean conducting a detailed analysis of each individual manuscript.

The standard script size in these manuscripts is between 2.5 and $3 \mathrm{~mm}$. A script consistently $2 \mathrm{~mm}$ or smaller can hence be called small and a script of $3.5 \mathrm{~mm}$ or more can be called large. Line division varies quite a bit more than script size even in a single manuscript but the average line division for most of these manuscripts falls between 6 and $8 \mathrm{~mm}$. Manuscripts with consistently smaller or larger divisions are thus noteworthy. Typically, the scribes followed the general size of the gaps between the dry lines by writing in a script that would fill slightly less than half of the available space, leaving room for letters extending below and above the lines. This further illustrates that the spacing desired for a manuscript was normally already decided when the dry lines for writing were drawn. But there do exist some exceptional cases where the scribes have decided to deviate from these standards indicated by the layout of the prepared manuscript at the time of writing. Nevertheless, this does show that line divisions and hence the appropriate script size were already decided when the manuscript was prepared for writing and was part of the conscious formatting choices that reflect the extent of the works to be written in the manuscript and its intended primary use. However, the scribe was instrumental not only in employing a script size consistent with the intended spacing of lines but for using letter and word spacing in line with the intended usage of a manuscript. Even if the script and line divisions are larger than normal but the words themselves are written practically without spacing, the manuscript would have been difficult to read, whereas a manuscript with small letters and line spacing but regular letter and word spacing would have been 
a relatively easy read at least in a private setting. While attention will be paid in the following to manuscripts that show distinct practices in many of the aforementioned areas, a case for the ritual use of some manuscripts falling just within the upper limit of the mentioned measurements could be made together with other criteria. Similarly, it would be difficult to argue simply on material grounds for an intended public use of manuscripts falling into the lower end of the established normal range.

For instance, 4QBerakhot ${ }^{\mathrm{a}}$ (4Q286) has the largest format among the Berakhot manuscripts. It has a line spacing at the upper reach of the normal range, close to $8 \mathrm{~mm}$, spacing of letters varying from normal to large, and a regular sized $3 \mathrm{~mm}$ script written in a formal hand. The contents of the manuscript are clearly a communal liturgy with "amen, amen"-refrains, and vacats used for divisions between different sections. Thus, this manuscript could well have been used in a public reading, but it falls just within the range of normal in all respects. A similar case is $1 \mathrm{QH}^{\mathrm{b}}(1 \mathrm{Q} 35)$ with a line spacing of $8 \mathrm{~mm}$, letter size of $3 \mathrm{~mm}$, and using paleo-Hebrew letters for Another communal liturgical text, 6Q18, also uses paleo-Hebrew for אל. The script is clear, neat, and rather large (between 3.5 and $4 \mathrm{~mm}$ ), and the line division varies from 6 to $10 \mathrm{~mm}$. This means that the manuscript could have been used in public gatherings, but the average formatting is on the upper reaches of the normal range or just barely above it. Finally, 11QapocrPs (11Q11), which I have previously argued is a possible public liturgical scroll, also falls into this range. ${ }^{12}$ It has a line spacing from 6 to $8 \mathrm{~mm}$, the average being c. $7 \mathrm{~mm}$, a regular sized $3 \mathrm{~mm}$ script, but markedly large letter and word spaces throughout. The individual psalms are divided by vacats, and the scroll has an "amen, amen"-ending, introduced as a response to the ritual by a community. In addition, the version of Psalm 91 at the end of the scroll has been modified in terms of personal forms to conform to the other psalms on the scroll so that one person can recite the whole scroll by addressing the person(s) afflicted by evil spirits and the evil spirits in turn. The general size of the scroll would also have made it easy to use in a public gathering without requiring a pedestal or someone else to hold it for the reader. I still maintain that this manuscript was probably intended to be used in a public exorcism ritual, but the material features of it are within normal range except for the spacing of letters and words. This case of 11QapocrPs serves well as an example where a more thorough study of a manuscript falling mostly within the normal range of spacing formats can result, with further argumentation, in a plausible claim that the manuscript could well have been used in a public ritual setting.

Finally, an example of a manuscript from the lower range of typical formatting is $5 \mathrm{Q} 14$. The script is rather small, varying from 2 to $2.5 \mathrm{~mm}$ with thick lettering, and the line spacing is c. $6 \mathrm{~mm}$. The word and letter spacing are normal in relation to the size of the script but the manuscript only had five lines and it is uncertain whether it had more than one column. The contents seem to be curses against human adversaries or more

12 Pajunen 2015, 128-161. 
probably evil spirits. It seems that this manuscript was most likely formatted for private use but again it falls just within the standard range in terms of readability factors. ${ }^{13}$

As can already be seen from the above examples, content can at times provide some additional clarification about the intended usage of a manuscript. In general, the works in this study are psalms and prayers that as a genre are open to both public and private use in ritual and educational settings. Works containing "amen, amen"refrains seem more plausibly to have had a ritual use than works without them. Compositions that contain a first or third person plural address describing the community participating in a ritual are perhaps slightly more likely to have been used in a communal gathering than works without such indicators. Most of the works in these manuscripts do not, in their current state of preservation, give an indication of when or where they would have been used, or only contain a short superscript about their use at a particular time. Such works could have been read from the scrolls on the appropriate occasions in ritual gatherings or as part of private piety. But there are also some manuscripts that contain both descriptions of when a certain psalm or prayer was to be uttered and acts accompanying the recitation. The clearest examples of such liturgies are purification rituals that present both the necessary acts of purification for different types of uncleanliness and the blessings to be recited afterwards by the purified person. Such manuscripts could have been used for checking the necessary acts by priests or literate persons purifying themselves, or for instructing others, but they are not ritual texts per se but rather descriptions of such rituals.

Finally, the use of the divine name deserves a brief mention. With two exceptions the tetragrammaton is only used in manuscripts containing now biblical material, either psalms or lamentations. The two exceptions are the apocryphal psalms of 11Q11 and a Deuteronomic communal prayer of confession in 4Q393. In all the other works in this survey other epithets of God are used and the tetragrammaton is avoided. This may most of all be an indication of the general date of these works, as the use of the divine name gradually diminishes from the second century BCE onwards. But if a ritual use of a text is considered at such a time period when pronouncing the divine name was atypical, an additional factor for not using the actual name in collections of psalms and prayers may have been the avoidance of the name in the text itself so as not to necessitate its replacement during recital. A similar caution may have been

13 This is one of the manuscripts highlighted by Pfann/Kister 1997, 7 as meant for private use because of its general size: "Most portable scrolls were owned by individuals and were intended to be carried about and read during certain feasts. Typically these scrolls contained 7-10 (and not more than 15) lines. Many of those included in this category comprised the biblical Megillot (Ruth, Song of Songs, Ecclesiastes, Lamentations, and Esther) including 2QRuth ${ }^{\mathrm{a}}$ (8 lines), 4QCant ${ }^{\mathrm{a}}$ (9 lines), 4QCant ${ }^{\mathrm{b}}$ (15 lines), 4QQoh ${ }^{\mathrm{a}}$, 4QLam (10 lines), 5QLam ${ }^{\mathrm{a}}$ (7 lines), and 6QCant (7 lines). A few liturgical texts are also portable scrolls: 4Q501 (4QapocrLam B, 9 lines), 4QShir ${ }^{\mathrm{a}}$ (9 lines), 5QCurses (5 lines). To these should be added several texts in Aramaic: 4Q246 (4QApocrDan, 9 lines), 4Q318 (4QZodiology and Brontology, 9 lines), 4Q542 (4QTQahat, 13 lines), 4Q550 (4QPrEsther ${ }^{\mathrm{a}-\mathrm{f}}$ ar, 7 lines). Perhaps to be added to these are 4Q180 (4QAges of Creat ${ }^{\mathrm{a}}$, 10 lines) and 4Q181 (4QAges of Creat ${ }^{\mathrm{b}}, 12$ lines).” 
MSS not formatted for easy readability
MSS formatted for private piety
MSS

formatted

for public

ritual use

Fig. 1: Possible overlaps in the use of MSS with different formatting.

behind the use of paleo-Hebrew characters for the tetragrammaton in some manuscripts, and even for 2 as seen above. The special layout of the divine name would have made it easy to distinguish the tetragrammaton from the rest of the text and to replace it in recital. Unfortunately, such observations remain on the level of the hypothetical because there is no conclusive evidence about how the divine name was handled in recitals during the late Second Temple period, only that it was avoided when writing new compositions.

In the following, some manuscripts will be highlighted that-by their material formats-were most likely intentionally formatted for public or private ritual use, or were probably not intended for such uses at the time the manuscript was written. Manuscripts possibly meant for public and private ritual use have the general easy readability of the manuscript in common, guaranteed by a particularly large spacing, and it is at times difficult to decide what would be the most plausible intended setting of a manuscript. Indeed, it may not always be pertinent to decide between such public and private ritual uses as the same manuscript could have been used in both kinds of settings. The manuscripts that are not formatted for such uses are most of all manuscripts that would have been extremely hard to read and often acted as repositories for larger quantities of material. But their use at least in private piety cannot be discarded just because they are not formatted optimally for easy readability. The overlap of these three spheres can be illustrated by the above image. Manuscripts in neighboring spheres might have been used on occasion in both but manuscripts at the far ends from each other would be difficult to argue as having been used in the setting at the opposite end.

\section{Manuscripts Formatted for Public Ritual Use}

In the following, some of the most plausible cases for psalm and prayer manuscripts intentionally formatted for public reading will be presented briefly. Some of these manuscripts are quite limited in terms of remaining material, which hinders the evaluation of their overall formatting. One such limitedly preserved manuscript is 1Q39, which is made up of ten small fragments. But the letters are on average $3.5 \mathrm{~mm}$, the 
typical line division is around $9 \mathrm{~mm}$ and the spacing of letters and words is rather large. This scroll would probably have been easy to read in public and the formatting indicates that this may have been its intended use. Two of the so-called psalms manuscripts are also quite limited in terms of remaining material and display some further peculiarities. 4Q91 has a script of 2 to $2.5 \mathrm{~mm}$ and a regular spacing between letters and words but an unusually large spacing of lines, from 9 to $10 \mathrm{~mm}$. Because the script is small in relation to the available space on the lines the formatting does not seem optimal for any particular use and there is a substantial amount of space that could have been better employed by the scribe, either by using a scroll with shorter line divisions or by employing a larger script. A contrasting format is found in 4Q93, which seems to have possibly contained only Psalm 104 in a stichometric arrangement. Even though the line divisions vary between 8 and $9 \mathrm{~mm}$ the script is larger than on 4Q91, from 3 to $3.5 \mathrm{~mm}$, and little or no space is left between words. This scroll would have been very difficult to use in public even though the hand and line divisions are slightly larger than the regular range. 4Q91 in turn could have been used in a public setting but the relatively small hand in relation to the line divisions is peculiar, even though it grants the appearance of a spacious layout. Yet another poorly preserved scroll with large formatting is 4Q292. It has letters of $3.5 \mathrm{~mm}$, an average line division of $9 \mathrm{~mm}$, and regular to large letter and word spaces in relation to the script. The remaining contents are from a communal prayer with an "amen, amen"-refrain preserved. This manuscript could thus potentially have been used in a communal liturgical setting (4Q471c may be a similar case but too little remains of it to establish this).

Fortunately, some of the plausibly public liturgical scrolls have been slightly better preserved. 4QFestival Prayers ${ }^{\mathrm{b}}$ (4Q508) consists of 41 fragments, albeit most of them are rather small. The script is of regular size, from 2.5 to $3 \mathrm{~mm}$, but letter and word spacing as well as space between lines $(8-10 \mathrm{~mm})$ are consistently large. The prayers are clearly communal, separated with vacats, and the manuscript contained “amen, amen"-refrains. A similar case is 4QSongs of the Sage ${ }^{a}$ (4Q510) that also has a regular-sized $3 \mathrm{~mm}$ script, but large word and line spacing (c. $8-10 \mathrm{~mm}$ ). The public use of both of these scrolls would have been quite easy and plausible in terms of format and content. 4QSongs of the Sage ${ }^{\mathrm{b}}$ (4Q511) presents an even more plausible case for use in a communal liturgical setting. It has larger script than 4Q510, the average being between 3.5 and $4 \mathrm{~mm}$, rather broad line spacing averaging around $8 \mathrm{~mm}$, and regular letter and word division. The individual songs are separated by vacats and the scroll has an "amen, amen"-ending. A final case to be mentioned among plausible liturgical texts written on parchment is the large psalm scroll from Cave 11,11QPs ${ }^{\text {a }}$. The long length of the scroll would have hindered its use somewhat, but the scroll is in a large format and of rather normal height. The height of the letters is consistently between 3 and $3.5 \mathrm{~mm}$, the letter and word divisions are large, and the line divisions vary between 8.5 and $10 \mathrm{~mm}$, i. e., consistently above the normal range. The tetragrammaton is written in paleo-Hebrew, vacats are used consistently between compositions, and many scholars have claimed that $11 \mathrm{QPs}^{\mathrm{a}}$ contains a more liturgical arrangement 
of material than the MT Psalter. ${ }^{14}$ The format is markedly different from the few Cave 4 psalms manuscripts that may originally have contained around the same amount of material (or more), like $4 \mathrm{Q} 83.11 \mathrm{QPs}{ }^{\mathrm{a}}$ is certainly a beautiful scroll that could easily have been used in a public setting, picking up appropriate psalms or psalm clusters.

The final manuscript to be mentioned as a scroll plausibly formatted for a public liturgical use is a papyrus manuscript, 4QpapHodayot ${ }^{\mathrm{f}}$ (4Q432). It has a large script of $4 \mathrm{~mm}$ and by a fair margin the broadest line division among the psalm and prayer manuscripts, ranging from 11 to $15 \mathrm{~mm}$. The space between letters is normal but the space between words is consistently large. In terms of material indicators this would be the best candidate for a scroll intentionally formatted for easy public reading, and, according to a material reconstruction of the manuscript, it contained a more limited collection than $1 \mathrm{QH}^{\mathrm{a}}{ }^{15}$ which further supports such a conclusion.

\section{Manuscripts Formatted for Private Piety}

As with the large reading format public ritual scrolls above, some of these manuscripts are also very poorly preserved. 2QPs (2Q14) is an intriguing case. It contains parts of Psalms 103 and 104, which may have been the only works on the scroll. A special feature in it is the use of red ink for a passage from Psalm 103 (vv. 1-4). This has been seen by Peter Flint as a potential sign of ritual use. ${ }^{16}$ This was a small scroll with column widths from 6 to $8 \mathrm{~cm}$. The script is neat with regular spacing, but the hand is only $1-2 \mathrm{~mm}$ in size and the division of lines varies between 4 and $5 \mathrm{~mm}$. These dimensions suggest that the manuscript was not intended for public ritual use, but may rather have been intended for private piety with the red ink marking the beginnings of the psalms for the reader. Another psalms manuscript, 4Q98g, is probably a personal note only containing an abbreviated and reinterpreted form of Nathan's prophecy from Ps 89:20 ff. ${ }^{17}$ It has a large script and line divisions from 7 to $8 \mathrm{~mm}$, but it has a number of scribal errors in a small amount of space and the ends of the lines are crowded together. This suggests that the intended text was crammed into a

14 For instance, Skehan 1973; Wacholder 1988.

15 Schuller 1999b, 212.

16 Flint 1997, 32. According to Tov 2004, 54 red ink is found only on three manuscripts from Qumran (4QNumb ${ }^{b}, 4 Q 270$, and 4Q481d), in addition to 2QPs, and appears to be a way of indicating the beginning of a sense division, such as a new psalm as in 2QPs, which is a practice also found in some Egyptian papyri. This rare use of red ink in the Qumran scrolls seems to indicate that it was probably not used by the Qumran community who appear to have used vacats and special signs in the margin to indicate sense divisions rather than red ink. Thus, these few scrolls with red ink were probably brought to Qumran from elsewhere. This could be an additional indication that 2QPs was a personal copy brought to Qumran by an individual rather than a scroll originally formatted for public ritual use. 17 See further Pajunen 2014. 
minimal space and reading it in public would have been difficult. A similar case is 4Q291, which has a very large $5 \mathrm{~mm}$ script, regular division between letters, and a typical line division of 10 to $11 \mathrm{~mm}$. These would point strongly towards public ritual use, but the text is written in a semi-cursive script, which is rare, and with short intervals between words. While public ritual use of this manuscript is certainly possible these features may rather suggest a private use.

Another exemplar of the Berakhot, 4Q287, has many of the same elements in terms of content as 4Q286 discussed above. It is a communal ritual text with "amen, amen"-refrains, and vacats used consistently for the division of material. But the format of 4Q287 is smaller than that of 4Q286 with thirteen lines per column, a small script from 2 to $2.5 \mathrm{~mm}$, and an average space between lines around $5.5 \mathrm{~mm}$. Taken together with a short spacing used for the division of words this manuscript seems more readily appropriate for private use rather than public ceremonies. ${ }^{18} 4$ QHodayot $^{\mathrm{a}}$ (4Q427) has regularly been seen as a liturgical collection because of its contents. ${ }^{19}$ The line division of c. $10 \mathrm{~mm}$ and the use of vacats support such a possibility. But while a public use cannot be refuted, the small script of 2 to $2.5 \mathrm{~mm}$, at times short spacing between words, and semi-cursive script might rather suggest a collection meant primarily for private piety.

Manuscript 4Q504 of the Words of the Luminaries is a parchment opisthograph containing prayers for each day of the week. It contains "amen, amen"-refrains, regular vacats, and instructions concerning the proper day for each prayer in addition to the actual text of the prayers. The letter and word spaces are quite normal, but the script is small and semi-cursive, and the line spacing short. This suggests a copy for private rather than public use. The manuscript also contains marks in the margin for easily finding the different prayers. This would have been a handy feature in a scroll where separate prayers would have been used on different days as the contents seem to indicate. The marks would have allowed for easy skimming of the contents to the appropriate prayer.

Three works on papyrus manuscripts also contain signs in the margins marking the beginnings of prayers. 4Q503 contains prayers for each day of a month, 4Q509 festival prayers, and 4Q512 purification rites. All of these prayers have a description of the appropriate time to pronounce a specific prayer and its wording (cf. the liturgical headings in some LXX psalms). The purification ritual also includes instructions on the appropriate means of purifying oneself before pronouncing the proper blessing. All of them have normal sized script and spacing of words and letters but their line divisions are short, which makes them appear crowded. Moreover, they are all part of opisthographs. 4Q503 and 4Q512 are actually part of the same manuscript, and 4Q509

18 Falk 2014, 70-71 estimates 4Q287 to be a portable copy.

19 For example, Schuller 1999a, 87 remarks that $4 \mathrm{QHod}^{\mathrm{a}}$ is more liturgically oriented than the other Hodayot collections. 
is on the same manuscript with other prayer texts, 4Q505 and 4Q506, and some War Scroll related material (4Q496). The fact that these two opisthographs contain almost entirely prayer material has given rise to suggestions about private copies for use while traveling. ${ }^{20}$ The material format agrees with this assessment in the sense that these manuscripts do not appear to be formatted for public ritual use. Yet the markings in the margins indicate a need to find specific prayers or purification instructions in a timely manner, and the contents are all prayers an individual could offer at specific times of day, on particular days, on feast days, and in relation to purification. ${ }^{21}$ Thus, these manuscripts seem most easily connected with private use.

\section{Manuscripts Not Formatted for Ritual Use}

The manuscripts that were probably not meant to be read aloud as part of public rituals are mostly distinguishable by a small script and with shorter spaces between words and lines than is typical (e.g., 4Q98a has a tall and narrow column of 60 lines, letters of $2 \mathrm{~mm}$ or less, and space between lines from 4 to $6 \mathrm{~mm}$, 4Q275 has a minute script of 1 to $1.5 \mathrm{~mm}$, and an average $5 \mathrm{~mm}$ spacing of lines, and 4Q369 has $2 \mathrm{~mm}$ letters and a line space between 5 and $6 \mathrm{~mm}$ ). These are often manuscripts where as much material as possible was crammed into the available space (regardless of whether the scroll was large or not). Two manuscripts, 4Q89 and 4Q90, provide an illustrative example of such differences in format. Both manuscripts probably originally contained only Psalm 119. 4Q89 is regular in its reading format: it has normal to large spacing of letters and words, line spacing of 6 to $8 \mathrm{~mm}$ as well as a $3 \mathrm{~mm}$ script. It also utilizes vacats between the stanzas of the Psalm. The manuscript is thus in the normal range in all of these matters. $4 \mathrm{Q} 90$ in turn has a script of $2 \mathrm{~mm}$ or less, line division average of $5 \mathrm{~mm}$, with normal space between letters and words, and no extant vacats. This scroll would have been much more difficult to use in a (public) reading than 4Q89, and both of these could be further compared with Psalm 119 on $11 \mathrm{QPs}^{\mathrm{a}}$ where the contrast with $4 \mathrm{Q} 90$ would be even more marked.

20 Cf. Tov 2004, 51, who considers it likely that most of the papyrus manuscripts from Qumran preserve personal copies. Falk 1998 envisions a communal liturgical occasion especially for the daily prayers but in this study he is more concerned with proving a liturgical use in general than with a differentiation between manuscripts meant for public and private uses. Moreover, his arguments in this study stem most of all from the contents of the work, not from the material evidence. In his more recent study, Falk 2014, he considers all these opisthographs, including 4Q504, to be almost certainly personal copies.

21 Note also Antony Perrot's analysis of these opisthographs in this volume, where he adduces additional evidence that these scrolls were probably not intended for continuous reading, but rather served as repositories for prayers taken up at appropriate times. 
In addition to such cases there are a few manuscripts where the letter size and spacing could be described as extra small or even miniature. For example, 3QLamentations has letters of only $1 \mathrm{~mm}$ with short spacing of words and line spacing varying from 4 to $5 \mathrm{~mm}$, making reading the text very difficult. A curious case are the manuscripts of the Songs of the Sabbath Sacrifice. Most of them are in a small reading format with letters of $2 \mathrm{~mm}$, line divisions around 4 to $6 \mathrm{~mm}$, and normal or short spacing between letters and words (e. g., 4Q400, 4Q401, and 4Q402). The smallest formatting in the collections containing the Songs of the Sabbath Sacrifice is found in 4Q403. While the word and letter spaces are normal in relation to the script and vacats are regularly used between songs, the hand is only 1 to $1.5 \mathrm{~mm}$, and divisions between lines from 3 to $4 \mathrm{~mm}$. These scrolls, and especially 4Q403, ${ }^{22}$ are not formatted for use in a public ritual setting but apparently rather contained a relatively large collection of songs in a minimum amount of space. ${ }^{23}$

The final manuscript dealt with here is another psalms manuscript, 4Q88. It has many peculiarities in terms of both formatting and content. It has a small, 2 to $2.5 \mathrm{~mm}$, semi-cursive script with short to normal spacing of letters and words, and a line division typically around $5 \mathrm{~mm}$. The manuscript was relatively tall with 23 to 25 lines, but the width of columns is only 12 to 30 letter spaces. This would have been an expected format for psalms in a stichometric arrangement, but no such psalms are extant on the manuscript. Rather the short columns are written tightly in a prose format, and it seems that there may not even have been vacats between psalms. The psalms also contain an unusually large number of small textual variants in relation to other psalms manuscripts, ${ }^{24}$ and Aramaic influence is evident at least in the case of the Apostrophe to Zion in relation to the version found in $11 \mathrm{QPs}^{\mathrm{a}} \cdot{ }^{25}$ Taking all of these indicators into account, it could well be that $4 \mathrm{Q} 88$ is a scroll written down at least partly from memory-accounting for the Aramaic influence - onto an existing piece of leather that was not ideally formatted for the scribe's needs, which apparently was to include as many psalms as possible in the available space. Regardless of whether this is the case, the scroll is definitely not a scroll prepared for public ritual use, but some kind of private collection of material.

22 Cf. Falk 2014, 70.

23 Cf. Schücking-Jungblut (in this volume).

24 See further Skehan/Ulrich/Flint 2000, 86-87.

25 According to the editors, Skehan/Ulrich/Flint 2000, 87, all the apocryphal compositions in 4 Q88 contain Aramaisms, but without comparative material, as is found with the Apostrophe to Zion, it cannot be shown whether this is a peculiarity of the versions in $4 \mathrm{Q} 88$ or an original trait in the compositions. 


\section{Conclusions}

In previous research many claims have been made concerning the possible uses of specific psalm and prayer manuscripts from Qumran. These arguments have been built mainly on the overall size of the manuscripts and their extant contents. In this paper it has been examined what would be the impact of investigating the readability of manuscripts on the basis of such claims. A survey was conducted of the 119 psalm and prayer manuscripts from Qumran that paid particular attention to those aspects that would have made a scroll easy or difficult to read, especially in a public setting. Before matters of material formatting were discussed, some general features common to nearly all of these 119 manuscripts were presented. According to this study a typical psalm or prayer collection from Qumran was written in Hebrew in a formal or semi-formal hand on a parchment manuscript and the scribe would have employed vacats to show divisions between different compositions. Unlike former studies this survey took the general size of individual scrolls into account only as auxiliary information, and the same is true for the contents of the works in the manuscripts. The main focus in this article was to find manuscripts that deviate from the normal range in regard to script size, and space left between letters, words, and lines because these factors would have directly impacted the readability of the manuscripts. Most investigated manuscripts naturally fell within the range of normal in all of these aspects or contained an abnormality only within one of these factors. But about thirty manuscripts fell significantly enough outside this range to be considered here as scrolls possibly meant for public reading, easy private use, or difficult to read at least in a public setting, and hence probably acting as repositories of compositions written in as condensed a manner as possible in the available space. Of course, such a study works on the level of probabilities and offers no certainties as to how a particular manuscript was actually used in its historical setting. Nevertheless, the analysis does reveal some manuscripts that were plausibly formatted by the scribe for easy reading and others where the readability of a text in public was not an issue for the scribe at the time the manuscript was prepared and inscribed.

Of course the crux of the matter is how much weight readability should be given in determining the plausible setting a manuscript was used in. In as far as the general notion among scholars stands that the size of the scroll, its height, width, margins, etc., were usually carefully chosen for the intended content and use of the scroll, the matters related to readability should also be taken into account as providing additional important evidence for such intentions. When viewing the different manuscripts individually on digital images that can easily be enlarged, these observations might seem inconsequential. However, when studied in actual size and preferably alongside manuscripts of similar general size but different formatting, the importance of these observations is readily observable. If the manuscripts with the smallest and largest reading formats are compared, a manuscript with a small format can contain three lines in the space where the large reading format scroll only has one 
and the impact of the script size on the available letter spaces in a column is in similar ratio. The impact on reading that such differences make is easily testable simply by modifying the font size and line spacing of texts by similar ratios in modern word processing programs. Naturally this is just one aspect in the materiality of the scrolls, but it should be more regularly incorporated as an important factor in future studies.

In this study only the clearest and most peculiar cases among the psalm and prayer manuscripts from Qumran were briefly presented. In future studies, all of these should be discussed in more detail, and holistic analyses should also be made, especially on the intended uses of specific manuscripts falling into the upper and lower reaches of "normal readability". Furthermore, these observations concerning readability and formats should be placed in a larger comparative framework by relating them to similar data gathered from manuscripts containing texts of other literary genres, such as narrative or legal works.

\section{Bibliography}

Davis, Kipp (2017), "Structure, Stichometry, and Standardization: An Analysis of Scribal Features in a Selection of the Dead Sea Psalms Scrolls", in: Mika S. Pajunen and Jeremy Penner (eds.), Functions of Psalms and Prayers in the Late Second Temple Period (Beihefte zur Zeitschrift für die alttestamentliche Wissenschaft 486), Berlin, 155-184.

Falk, Daniel (1998), Daily, Sabbath, and Festival Prayers in the Dead Sea Scrolls (Studies on the Texts of the Desert of Judah 27), Leiden.

Falk, Daniel (2000), “Reconstructing Prayer Fragments in DJD VII”, in: Lawrence Schiffman, Emanuel Tov and James C. VanderKam (eds.), The Dead Sea Scrolls Fifty Years after Their Discovery: Proceedings of the Jerusalem Congress, July 20-25, 1997, Jerusalem, 248-255.

Falk, Daniel (2014), “Material Aspects of Prayer Manuscripts at Qumran”, in: Clemens Leonhard and Hermut Löhr (eds.), Literature or Liturgy? Early Christians Hymns and Prayers in Their Literary and Liturgical Context in Antiquity (Wissenschaftliche Untersuchungen zum Neuen Testament 363), Tübingen, 33-88.

Flint, Peter (1997), The Dead Sea Psalms Scrolls and The Book of Psalms (Studies on the Texts of the Desert of Judah 27), Leiden.

Nitzan, Bilhah (1994), Qumran Prayer and Religious Poetry, trans. Jonathan Chipman (Studies on the Texts of the Desert of Judah 12), Leiden.

Pajunen, Mika S. (2013), The Land to the Elect and Justice for All: Reading Psalms in the Dead Sea Scrolls in Light of 4Q381 (Journal of Ancient Judaism-Supplements 14), Göttingen.

Pajunen, Mika S. (2014), “4QPs $-A$ Collective Interpretation of Psalm 89:20-38”, in: Journal of Biblical Literature 133 (3), 479-495.

Pajunen, Mika S. (2015), "How to Expel a Demon: Form- and Tradition-Critical Assessment of the Ritual of Exorcism in 11QapocrPs", in: Mika S. Pajunen and Hanna Tervanotko (eds.), Crossing Imaginary Boundaries: The Dead Sea Scrolls in the Context of Second Temple Judaism (Publications of the Finnish Exegetical Society 108), Helsinki, 128-161.

Pajunen, Mika S. (2017), “Exodus and Exile as Prototypes of Justice: Prophecies in the Psalms of Solomon and the Barkhi Nafshi Hymns", in: Mika S. Pajunen and Jeremy Penner (eds.), Functions of Psalms and Prayers in the Late Second Temple Period (Beihefte zur Zeitschrift für die alttestamentliche Wissenschaft 486), Berlin, 252-276. 
Pajunen, Mika S. (2019), "The Influence of Societal Changes in the Late Second Temple Period on the Functions and Composition of Psalms", in: Scandinavian Journal of the Old Testament 33 (2).

Pfann, Stephen/Kister, Menahem (1997), "Words of the Maskil to All Sons of Dawn", in: Torleif Elgvin et al. (eds.), Qumran Cave 4.XV: Sapiential Texts, Part 1 (Discoveries in the Judaean Desert 20), Oxford.

Schuller, Eileen (1999a), “427. 4QHodayota”, in: Esther Chazon et al. (eds.), Qumran Cave 4.XX: Poetical and Liturgical Texts, Part 2 (Discoveries in the Judaean Desert 29), Oxford, 77-124. Schuller, Eileen (1999b), “432. 4QpapHodayot”, in: Esther Chazon et al. (eds.), Qumran Cave 4.XX: Poetical and Liturgical Texts, Part 2 (Discoveries in the Judaean Desert 29), Oxford, 209-232.

Skehan, Patrick (1973), “A Liturgical Complex in 11QPs르", in: Catholic Biblical Quarterly 35, 195-205. Skehan, Patrick/Ulrich, Eugene/Flint, Peter (2000), "88. 4QPs", in: Eugene Ulrich et al. (eds.), Qumran Cave 4.XI: Psalms to Chronicles (Discoveries in the Judaean Desert 16), 0xford, 85-106. Tov, Emanuel (2004), Scribal Practices and Approaches Reflected in the Texts Found in the Judean Desert (Studies on the Texts of the Desert of Judah 54), Atlanta.

Wacholder, Ben Zion (1988), “David's Eschatological Psalter: 11QPsa””, in: Hebrew Union College Annual 59, 23-72.

\section{Photo Credits}

Fig. 1: Mika S. Pajunen. 